\title{
Teaching About Electricity in Primary School Multimodality and Variation Theory as Analytical Lenses
}

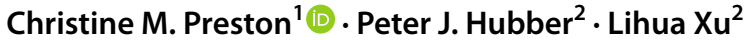

Accepted: 17 January 2022 / Published online: 2 March 2022

(c) Crown 2022

\begin{abstract}
Primary school topics involving abstract concepts are challenging to teach. Electric circuits can be simply constructed but complex to explain. New approaches in teaching students for understanding are needed to advance practice in primary science. This paper combines the strengths of multimodality research perspectives with variation theory to provide insights into a teaching sequence designed for year 6 students. Application of a representation construction approach (RCA) provides opportunities for multimodal meaning-making of electric circuits. The case study adopted a design-based research method to investigate teaching electric circuits. Data collection involved video capture of classroom practice, teacher and student interviews, student journal entries and assessment artefacts, field notes, and pre-test and post-test results. Design principles included identifying key ideas, devising a lesson sequence emphasising energy transfer and transformation, hands-on exploration using multimodal representations in response to learning challenges, and student journaling. Students' metarepresentational competence was also developed through evaluation, negotiation, and creation of representations and models of electric circuits. Representational challenges followed by strategic teacher-led discussion facilitated students' developing understanding through focusing attention on critical features. Deep learning was evidenced by journal records, formative and summative assessment artefacts, and post-test responses. RCA principles were instrumental in the successful design of an effective teaching sequence through focus on critical aspects of energy. We advocate a RCA for the design of a multimodal learning sequence. Variation theory was a useful analytical framework to understand the enactment of the design sequence. The study contributes to the challenge of rethinking traditional teaching practices in primary science.
\end{abstract}

Keywords Representations $\cdot$ Multimodality $\cdot$ Variation theory $\cdot$ Primary science $\cdot$ Social semiotics

Christine M. Preston

christine.preston@sydney.edu.au

1 Sydney School of Education and Social Work, The University of Sydney, Sydney, Australia

2 School of Education, Deakin University, Melbourne, Australia 


\section{Introduction}

Helping primary students understand physics concepts, especially when they are not visible, is problematic for teachers. Teaching science is a multimodal communication endeavour (Van Leeuwen, 2005) that involves learners making meaning through negotiating shared representations (Jewitt, 2008; Lemke, 1998). We apply multimodality and variation theory as theoretical lenses to better understand the possibilities for teaching about electric circuits in year 6 . Whilst electric circuits are simple to construct, students require instructional guidance to develop explanatory accounts of observable and functional processes using abstract ideas associated with energy and electric current (Jaakkola et al., 2011; Preston, 2017). Standard teaching practice that relates electric circuit behaviour using sophisticated canonical representations and models befitting senior secondary level are ineffective. The water reticulation and electric field models do not suit primary age students (Hart, 2008). We argue that the complexity of electric circuits might be better understood by younger students using age-appropriate representations and models.

A representation construction approach (RCA) where students construct and use representations to actively explore abstract concepts has been successful with different science topics (Hubber et al., 2010; Hubber \& Chittleborough, 2015). Inquiry-based approaches enhance student engagement and support successful learning of science (Chi, 2009; Furtak et al., 2012). A RCA employs guided inquiry and involves students conceptualising and reasoning through representations.

In this study, we address two research questions:

1. How can a RCA facilitate the design of a multimodal teaching sequence on electric circuits for primary students?

2. How was the teaching sequence enacted to draw students' attention to concepts underlying electric circuits?

In our attempt to understand the design and enactment of the teaching sequence underpinned by a RCA, we draw upon two complementary theoretical perspectives. We use multimodality and variation theory to identify how the teacher's employment of multimodal representations can facilitate student meaning-making about electric circuits. From a multimodal perspective, learning of electric circuit concepts is understood as meaning-making through and across various modes (Kress et al., 2014). This perspective focuses our attention on the diversity of semiotic modes and resources used in the classroom. Variation theory (VT) focuses our attention on the discernment of a concept (a learning object) through variations in its critical features (Lo, 2012; Marton, 2014; Tan et al., 2020). This VT perspective provides us with a language to describe how the teacher selected and sequenced semiotic resources in ways to draw students' attention to the critical aspects of the intended electric circuit concept. Through the combined use of the theoretical perspectives, we seek to better understand the teacher's selective use of semiotic resources and to clarify and bring together critical aspects of the intended concepts related to electricity. 


\section{Teaching Primary School Electricity}

The primary school electricity topic usually involves making simple electric circuits, but learning remains at a phenomenological level without understanding how they work (Chapman, 2014). Whilst more complex circuits are explored in secondary school, the Australian science curriculum expects year 6 students to operate and explain simple electric circuit function from an energy perspective:

Electrical energy can be transferred and transformed in electrical circuits and can be generated from a range of sources (ACARA, 2019).

The US Next Generation Science Standards (National Research Council, 2013) has a similar emphasis on energy.

Primary students enter classrooms with pre-instructional ideas about electricity from abundant use in their daily lives, though common alternative conceptions persist into secondary level. Interchangeable use of terms electricity, current, power, and energy mirrors their use in everyday language. Frequently, a "sink model" (Fredette \& Lochhead, 1980) is conveyed by students thinking the battery stores electricity/power/current, which flows to the bulb and gets consumed. The everyday phrases such as "charging batteries" or "batteries go flat" support this alternative conception (Hubber, 2018).

Students can physically construct circuits without comprehending the underlying processes including energy transfer, transformation, and current. Prain and Waldrip (2006) revealed many students "struggled to explain the concepts involved" in functioning of circuits they had constructed in class (p. 1854). Explanations of electric circuits draw on abstract ideas (Chapman, 2014) and models. These highly abstract models use the submicroscopic domain to explain electric circuit behaviour. The lack of suitable primary level models (Hart, 2008) is challenging for teachers (Hubber, 2018; Jaakkola et al., 2011); thus, a different approach to electric circuits is required.

Students' initial undertaking of inquiry-based, hands-on practical and simulation activities, related to real-world contexts, provides insights into the macroscopic world of electric circuits (Aboagye et al., 2018). According to Chiu and Lin (2005), students can be supported to delve into sub-microscopic aspects of electric circuits using simplified analogical models of energy transfer and transformation. We argue that the complexity of electric circuits might be more fathomable in primary school through a representation construction approach.

\section{RCA: a Guided Inquiry Pedagogy}

Classroom studies have investigated representations in teaching and learning science (Carolan et al., 2008; Cox, 1999; diSessa, 2004; Greeno \& Hall, 1997; Prain et al., 2007; Tytler et al., 2006). Finding stress meaning is negotiated through coordinating different modes of communication (verbal, visual, mathematical) and gestural representations of scientific ideas and processes. Learning in science necessitates moving between, integrating, and producing meaning of, often abstract or technical ideas, through various representational forms (Kress et al., 2014). The role of representations encapsulates both learning from and learning with representations (Tang et al., 2014).

RCA is a research-grounded guided inquiry approach, whereby students construct and evaluate representations, leading to understanding and productive use of scientific 
representations (Hubber et al., 2018; Tytler et al., 2020; Waldrip et al., 2010). Representational challenges involve students constructing their own and critiquing others' representations (text, graphs, models, diagrams) to actively explore and make claims about phenomena. Students negotiate representations provided by the teacher along with self-generated representations to discuss and explain phenomena and concepts. Four principles underlie a RCA:

1. Teaching sequence based on sequence of representational challenges.

2. Representations are explicitly discussed.

3. Meaningful learning involves representational/perceptual mapping.

4. Formative and summative assessment is ongoing (Tytler et al., 2013, p. 34).

This study aims to elucidate how the RCA might scaffold a teacher to design a conceptually based teaching sequence about electric circuits.

\section{Multimodality}

Social semiotics is concerned with meaning-making as multimodal communication. Multimodality in the science classroom takes meaning-making of concepts beyond textual and verbal representations (modes) of reality. Kress et al. (2014) explain "learning happens through all modes as a complex activity in which speech or writing are involved among a number of modes" (p. 1). Since specific modes have different affordances, multimodal learning environments provide opportunities for students to engage with the scientific concepts and processes through multiple semiotic resources (SRs).

We define SRs as actions and artefacts used to communicate ideas and make meaning (Van Leeuwen, 2005). Students make meaning through an array of semiotic modes, including language (speech and writing), image, and action (Kress et al., 2014; Lemke, 1998). Multimodality combines modes, for example, a video about the greenhouse effect is a semiotic resource that mixes a variety of modes (moving images, speech, text, or captions) to communicate ideas. SRs vary in form, with each integral to the meaning-making process. Visual SRs, for example, can variously represent information (graphs, tables, infographics, and diagrams). The standard electric circuit diagram is a canonical representation used by electricians, manufacturers, scientists, teachers, and students. It conveys spatial arrangements of circuit elements depicted by symbols (De Carvalho, 2019). SRs that explain things very well grant affordances, others that explain less well, or not at all, present constraints (Fredlund et al., 2021; Gibson, 1977). The way a mode has been used to mean and do (past) and the social conventions that inform its contextual use (present) shape its affordance (Jewitt, 2008; Van Leeuwen, 2005). An electric circuit diagram is a SR that represents the spatial arrangements of electrical components well but does not explain their functions.

The potential to express meaning in image (e.g. graphic markings on a two-dimensional surface) differs from the meaning potential of speech (recognisable sounds) (Jewitt, 2008; Lemke, 1998). Teachers must strategically select and connect available semiotic resources most apt to convey the meaning they want to express at a given moment for their students (Kress et al., 2014). We argue that multimodality theory allows us to analyse how multiple SRs interact to support student meaning-making about electric circuits during the teaching sequence. Variation theory complements the 
multimodality perspective in exemplifying how the teacher directs student attention to the critical aspect required to explain electric circuit function.

\section{Variation Theory}

Grounded in phenomenography, variation theory (VT) describes how a learner comes to understand the world through identifying the qualitatively different ways of experiencing (Marton \& Booth, 1997). Underpinning VT is the anatomy of awareness. Experiencing something as something requires differentiating it from other things and relating it to a specific context, discerning its parts, and relating it to the whole (Marton \& Booth, 1997). Thus, a way of experiencing is constituted by the simultaneous discernment of certain features (Runesson, 2005). The notions of discernment and simultaneity are essential characteristics of ways of experiencing (Lo \& Marton, 2011). When certain aspects of the phenomenon vary whilst other aspects remain invariant, those aspects that vary are likely to be discerned. We can only discern what varies, and what we discern is the "dimension of variation" (Pang, 2003; Runesson, 2006). Aspects that are attended to simultaneously are discerned as a pattern of dimensions of variation (pattern of variation). To discern the critical features of an object of learning (e.g. the concept energy), the learner must experience the potential alternatives or variations in the relevant aspects of a situation against the background of sameness. Marton et al. (2004) identified four patterns of variation:

- Contrast: experiencing something else that can be compared with.

- Generalization: experiencing something in various forms to separate it from other irrelevant features.

- Separation: to experience "a certain aspect of something" and "separate this aspect from other aspects, it must vary while other aspects remain invariant".

- Fusion: aspects of something must be varied together to provide opportunities for them to be experienced simultaneously (p.16).

Contrast and generalization are patterns of variation taking place in one single aspect. Separation and fusion deal with variations in two or more aspects. Marton (2014) identified the stages necessary in a learning sequence: "Contrast - Generalization - Fusion" (p. 54). Learning requires moving the experience of a learner "from an undifferentiated whole, through differentiation and integration, towards a differentiated and integrated whole" (p. 53).

Applying a VT perspective to science teaching focuses on "critical aspects" of a phenomenon that students need to notice. Also, the patterns of variation opened in relation to such critical aspects. VT provides a framework to identify what in a learning situation enables student discernment. This complements the multimodal analysis of how a pattern of variation was made available (e.g. using multiple semiotic modes to describe the same aspect of the phenomenon). Our interest is exemplifying how design and enactment of a teaching sequence provides possibilities for upper primary students' meaning-making about electric circuits. Examination of the semiotic resources the teacher selects can reveal how lesson tasks direct students' focal awareness towards critical aspects. 


\section{Complementary Theoretical Perspectives}

Other researchers have combined social semiotics and VT to analyse learning in physics (cf Eriksson et al., 2020). Fredlund, Linder, and Airey (2015a) propose a semiotic approach for use in identifying critical aspects in a university-level physics text. These authors suggest three factors to enhance learning from physics representations: identify critical aspects, select representations, and create variation (Fredlund, Airey, \& Linder, 2015b). Research involving upper secondary students' learning about the greenhouse effect revealed how affordances of certain modes may impact possibilities for learning (Fredlund et al., 2021). Our study furthers this work by analysing semiotic resource use in teaching electric circuits at the primary level.

\section{Methodology}

The 2-year case study was implemented through design-based research (Anderson \& Shattuck, 2012). An interactive process of development, trialling, and evaluating outcomes, occurred with the teacher partner. A science specialist teacher and two year 6 classes from a non-government girls' school participated in consecutive years. Professional learning comprised RCA principles, pedagogical content knowledge (PCK), and analogical models. Multiple data sources (classroom practice videos, teacher and student interviews, student journal entries, and field notes) captured the multimodal teaching sequence.

\section{Design Principles of the Teaching Sequence}

The key ideas underpinning the teaching sequence are characterised in the declarative statements (Table 1) comprising the intended objects of learning. The abstract concept of energy was treated as a "quasi-material" substance, which could then be represented in multiple modes as quanta flowing through a system. Whilst not scientifically correct, this view of energy "is not a serious hindrance to the later development of a more precise scientific understanding of energy" (Miller, 2005, p. 12). Adopting a RCA, students were introduced to and created multiple representations. Energy type, transfer and transformation, and electrons were represented to help explain electrical circuit behaviour. The static and dynamic SRs detailed in the lesson sequence have been described elsewhere (Preston et al., 2020).

\section{Data Analysis}

This analysis aimed to identify how the teacher used multimodal representations (SRs) to guide students' attention towards critical features of the object of learning (concepts underlying phenomena). The retrospective analysis took several steps:

1. Teacher interviews and planning documents were used to identify the focus for each lesson (intended object of learning) and its critical features. 


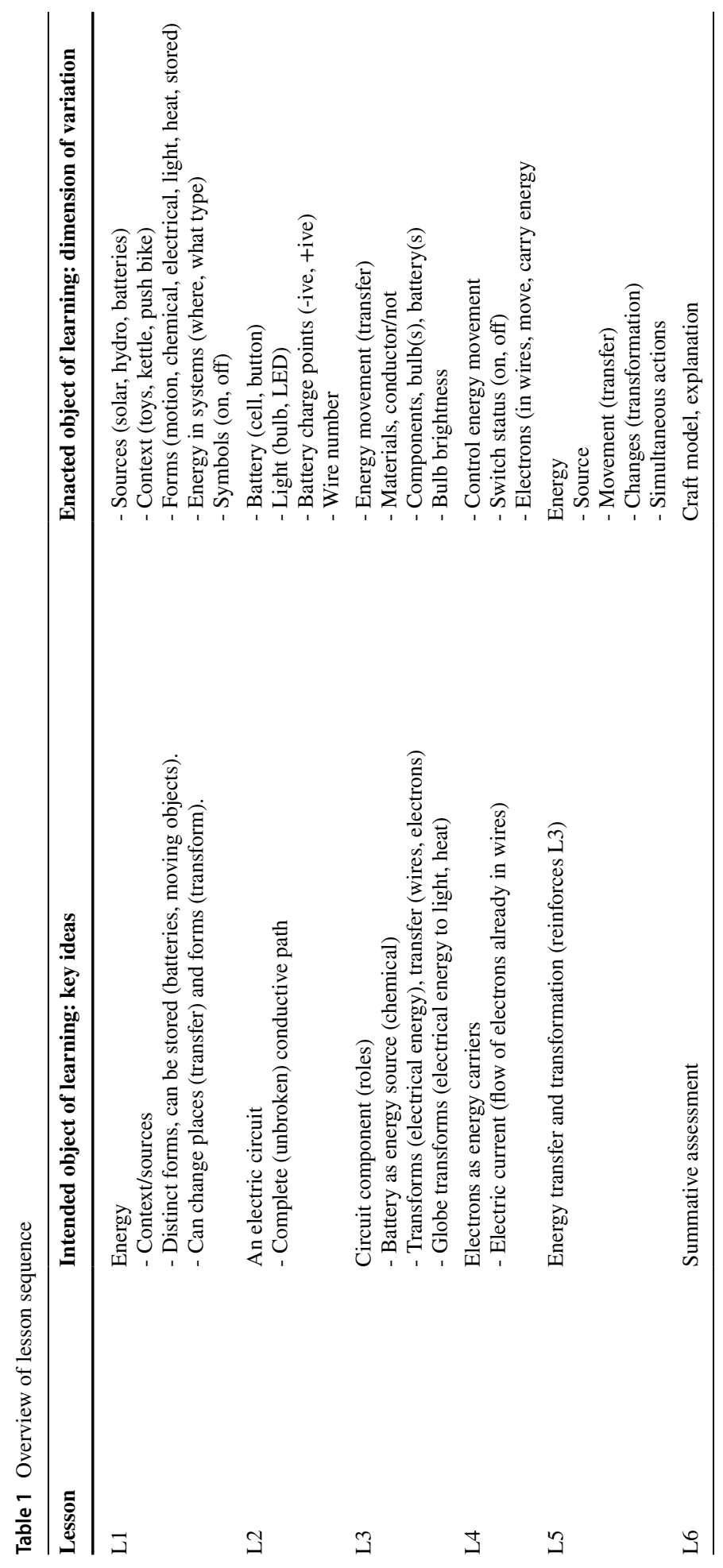


2. Video recording of lessons was used to identify and describe how learning manifested in the classroom (enacted object of learning). The modalities used to draw students' attention to dimensions of variation and diversity of representations and modes the teacher used were identified.

3. Specific segments were transcribed in detail allowing close analysis. The verbal interactions and representations that "opened up" dimensions of variation (e.g. types of energy) were identified.

This analysis combined the two theoretical approaches to scrutinise the teaching episodes. We identified how the teacher coordinated between multimodal representations to support the students' meaning-making. Teacher actions are essential in guiding students to attend to vital elements (Yeo \& Nielsen, 2020). VT provides a framework to analyse the multimodal interactions occurring in the classroom from different perspectives (teacher, researcher, and learner). VT enabled us to identify the relationship between what was intended by the teacher and what was made possible in the classroom. Student-generated representations were used to illustrate how students responded to the representational challenges. Multimodal analysis complemented VT to identify how the intended object of learning was enacted. This involved the teacher's actions, instructional tasks, multimodal representations, and teacher-student interactions. The multimodal analysis provided valuable insight into the social semiotic process of constructing meaning mediated by representational affordances.

\section{Results of Analysis}

We illustrate how the multimodal experiences were leveraged and what types of variation were "opened up" to enable students to attend to critical aspects of the intended learning objects in each lesson. Evidence of interpretation and construction of multimodal representations by students helps unpack their progressive meaning-making. We consider what SRs are used and what pedagogical moves guide students to notice critical features. Table 1 shows the intended object of learning that was presented in each lesson (column 2) and the enacted object of learning and the dimensions that were varied to focus students' attention (column 3).

The sequence was designed to provide a cumulative learning experience for students who interpreted and constructed a range of multimodal representations. Specific SRs were selected by the teacher to illustrate the critical aspects pertaining to electric circuits. The summative assessment (lesson 6) involving students constructing a physical representation of a circuit and explaining how it works is not included in this paper.

\section{Multimodal Enactment of Patterns of Variation in the Sequence}

Using three examples from the lesson sequence, we demonstrate how the teacher guided the students to attend to critical aspects of the target concept via a diverse range of SRs. These examples were chosen because each illustrates the use of a different multimodal ensemble to support the opening of dimensions of variation of the intended object of learning. These examples provide insight into the affordance of the SRs and multimodal interactions. Each facilitated student noticing of critical features required for meaning-making about energy in electric circuits. 


\section{Example 1: Elicit and Focus on Ideas About Energy}

In lesson 1 the students were expected to make energy-related observations to help them discern critical ideas about energy (different forms, travels between objects, and changes forms). Kate used a diverse range of SRs to introduce these key ideas about energy (verbal, visual, physical, and embodied modes). Each SR served a particular purpose in this lesson (Table 2). For example, Kate demonstrated how a toy car hitting a tin illustrate the types, transfer, and transformation of energy. Students then experienced identifying energy themselves through repeated physical manipulation with toys and then through embodied movement. Their initial ideas about energy were consolidated using an animation, verbal discussion, and visual and written representations, generated by the students and the whole class.

The above illustrates how Kate created a rich multimodal learning experience for the students. The following details show how she used an animation to discuss the transfer and transformation of energy in systems to reinforce key energy-related ideas. Table 3 shows excerpts from the video transcript of lesson 1 demonstrating how verbal discussion (column 1) was juxtaposed with the multimodal representation (column 2).

In this example, Kate strategically used the PhET animation (https://phet.colorado. edu/), switching between static and dynamic modes to draw student attention to the critical aspect of energy in the system. She used questioning to guide students to notice the transfer of energy through the system referring to the static images (rows 1-5). Kate directed

Table 2 Lesson 1 semiotic resources and purposes

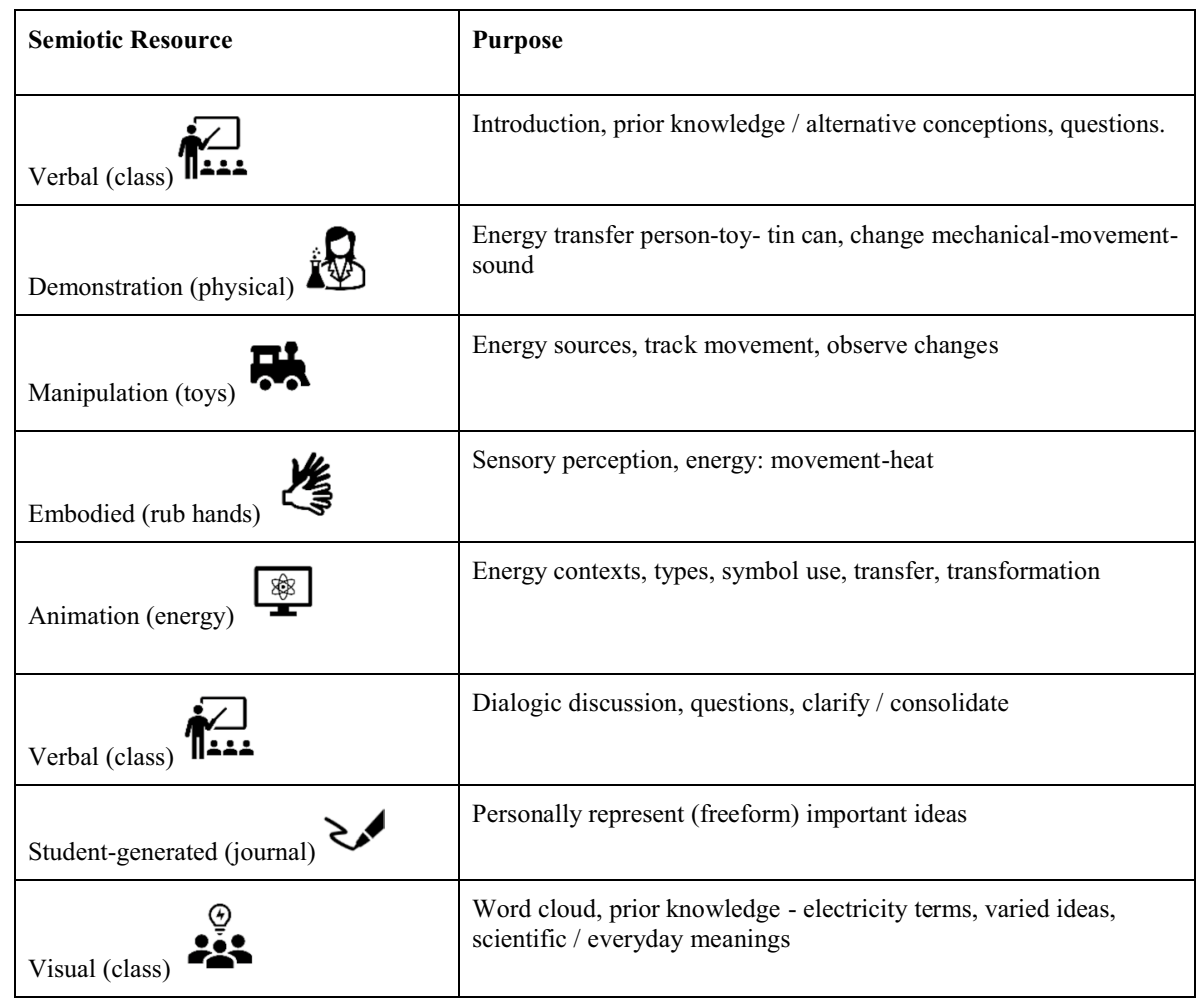


Table 3 Types of energy in the system

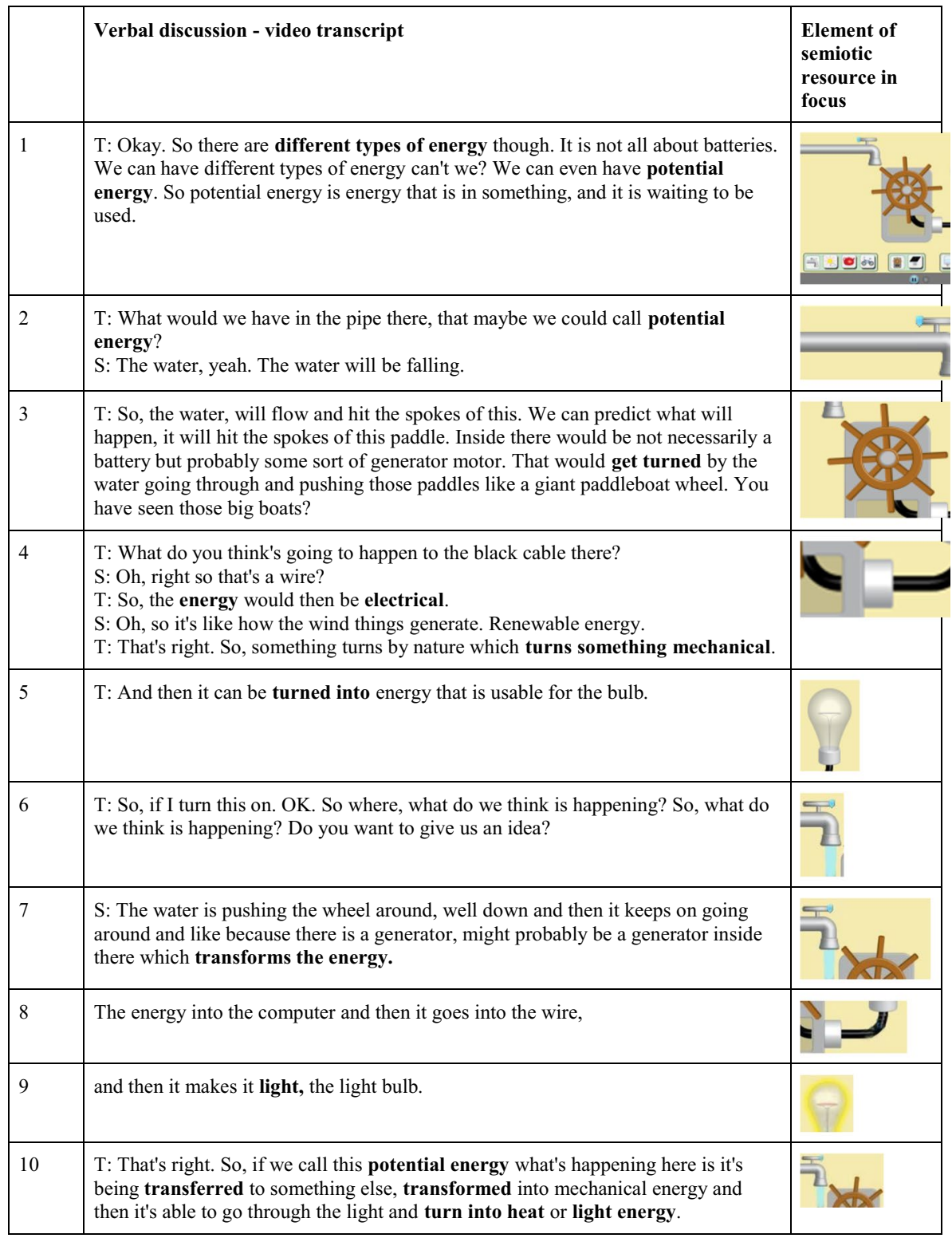

students to notice the positions of energy between parts of the system. Juxtaposing the verbal descriptions (e.g. electrical energy) and visual part (e.g. black cable) provided students with opportunities to discern energy transfer through the system. The bolded phrases in the transcript emphasise the key ideas Kate expected the students to notice. She turned the simulation to dynamic mode allowing students to track the flow of energy in the system from the water tap to the light bulb and to track the process of energy transformation (rows 6-10). The class discussion of the dynamic mode focused on how the energy changed to 
consolidate the idea of energy transformation. Finally, symbol activation pinpointed the flow of energy through parts of the system (see Fig. 1). Animations including chemical energy stored in food, solar energy, and "pedal power" also helped students discern energy transfer and transformation in different contexts, relating to everyday life.

Table 4 outlines a VT analysis of classroom interactions with the PhET animation and shows how Kate directed students' attention to discrete ideas using the multimodal affordances. Our analytical focus on the interplay between the spoken dialogue and the multimodal representations used shows the integration of SRs and the importance of the verbal mode for clarifying and consolidating student learning.

Applying VT, we identified patterns of variation in classroom interactions that helped students discern critical aspects (those that were varied) against a background of other aspects that were not varied (invariant). In the following analysis, the words in italics indicate dimensions of variation.

Example 1 shows how the sequential (or simultaneous) use of multiple SRs (e.g. visual, verbal, and dynamic) provided opportunities for the students to discern the critical aspects of the energy concept (column 3, Table 4). Introducing the system parts in static mode first drew student attention to the types of energy. The dynamic mode then provided variation and afforded students to identify the change between energy types and to differentiate between the transfer and transformation of energy in systems. This emphasis provided the background knowledge for students to approach thinking about electric circuits from an energy perspective in subsequent lessons. Representing the abstract energy concept as a quasi-material substance (Miller, 2005) in the animations gave students a way to visualise the multi-faceted nature of energy in terms of type, transfer, and transformation. This representation of energy appropriately materialises the construct and allows primary school students to discern underlying ideas. This initial lesson provided the students with the representational tools to develop an explanation of electric circuits later in the teaching sequence.

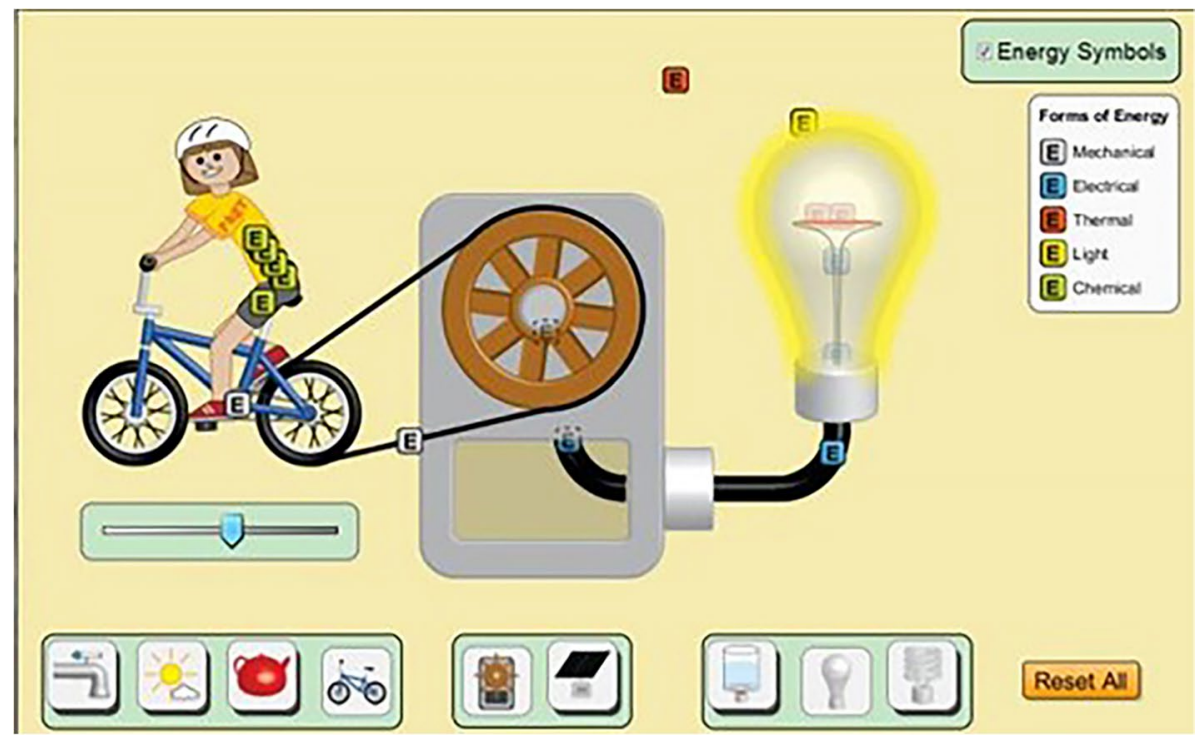

Fig. 1 Screenshot of second digital animation (PhET https://phet.colorado.edu/) 


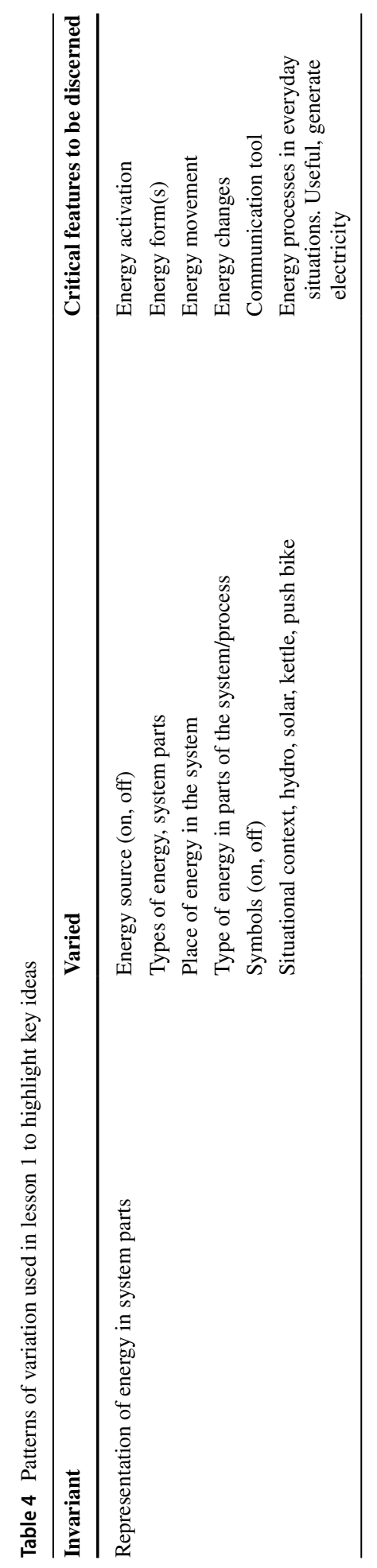




\section{Example 2: Use of Multiple Representations to Develop Ideas About Electric Circuit}

In example 2, we show how Kate used multiple representational modes to guide students' exploration of the macroscopic, observable effects of electric circuits. In lessons 2, 3, and 4, students were engaged in hands-on practical work with electric circuits responding to representational challenges and inquiry questions:

- Challenge 1: can you use a battery, bulb, and single wire to make the bulb light? (Lesson 2)

- Challenge 2: can you read circuit diagrams to make circuits? What is the effect of number of bulbs or batteries? (Lesson 3)

- Challenge 3: can you find a way to control energy by making a component to turn energy on and off? (Lesson 4)

We show through this multi-lesson sequence Kate's use of diverse SRs. She provides students with rich multimodal learning experiences focusing one at a time on critical aspects of electric circuits:

1) Macroscopic characteristics (e.g. components, arrangement, connection)

2) Symbolic and canonical representations

3) Microscopic explanations (e.g. energy transfer through electron flow)

Significant time was dedicated to developing and reinforcing these discrete ideas. Through verbal interactions with groups during investigations, Kate consciously focused student attention on critical aspects of circuits.

Lesson 2 commenced with challenge 1. Whilst students worked in small groups, Kate prompted them to try different ways, e.g. "lay the battery down" and "look where the wire is touching". Using journals to represent attempts provided opportunities for students to visualise and consider further possibilities and identify successful arrangements (Fig. 2a). Realising the requirement of a connected pathway (closed circuit) was reinforced through brief whole class discussion. In a second hands-on task, students used a kit containing assorted circuit components to explore battery and light types and answer questions such as "what materials conduct electricity?" and "what is an LED?" (Fig. 2b). Students were then tasked with annotating a light bulb diagram (Fig. 2c) to show a macro-view of challenge 1 .
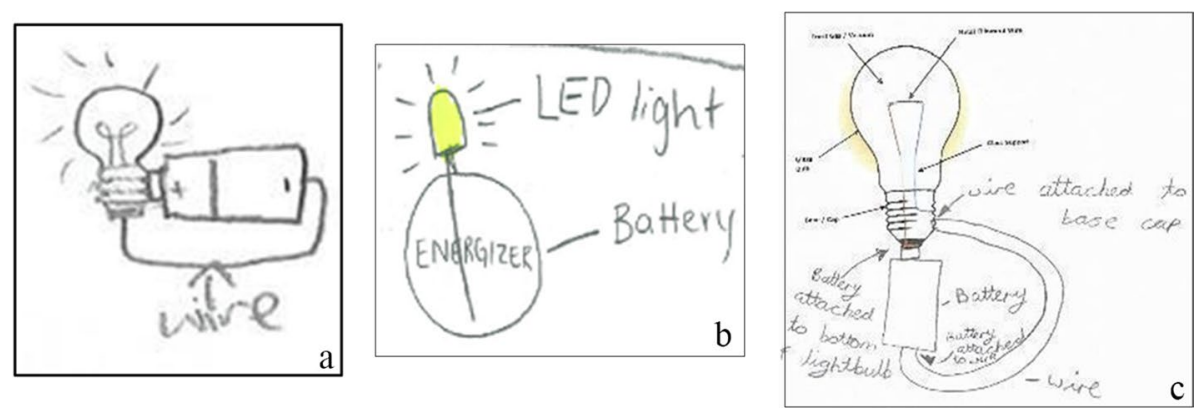

Fig. 2 a, b Student journal representation, $\mathbf{c}$ visual diagram annotated by student 
Various SRs were used in this lesson, often together, to support students developing understanding of aspects of electric circuits, for example, physical construction of electric circuits with different battery and bulb types. Manipulating materials provided opportunities to discern required arrangements and functions of different components and to notice specifics like positive and negative charge points. The bulb challenge aimed to direct students noticing of a continuous loop connecting the two charge points of a battery to activate energy. Annotation of the visual bulb diagram (Fig. 2c) helped students visualise reasons for success (or not) of their attempts at solving the challenge.

In lesson 3, Kate showed some student representations from lesson 2 and discussed what they did and did not show. This guided students to think critically about the effectiveness of their representations for communication. Kate introduced canonical circuit diagrams (Fig. 3a) to raise awareness of drawing efficiency and fidelity of meaning and symbol use in communication. Students followed printed circuit diagrams to construct physical circuits and observe the effects of adding bulbs or batteries. This continued hands-on exploration introduced variation in components of a circuit (battery/light type, connections, number of wires) to provide opportunities for students to learn about parts of a circuit separately.

Linking to the energy concept from lesson 1 gave students opportunities to develop explanations for various arrangements of circuit components from an energy perspective, within the system (see Fig. $3 b$ for an example of student representation). In this case, students were encouraged to think about the role of each component in circuit function. For example, the battery provides energy, and more batteries increase bulb brightness. The bulbs rely on available energy, and more bulbs decrease brightness because energy is shared.

Creating a switch (challenge 3 ) in lesson 4 helped students to consider energy as being dynamic, capable of travelling from one part of the circuit system (battery) to another (bulb). The realisation that energy can be made to move (or not move) prompted students to think about how it moves. An essential step in theorising and making sense of what they cannot see required use of a different SR. Figure 4 shows students adopted symbolic forms to represent circuits and suggested creative analogies of switch function such as the likening the switch to a gate.

The use of the PhET animation (Fig. 5a) allowed students to "see" inside wires. As students experimented with adding batteries or testing materials for conductivity, Kate encouraged small groups to verbalise ideas about their observations. The digital PhET animation afforded a microscopic view representing what was happening inside the wires. Students could observe immediate effects of changes made inside the wires that were not possible in a physical circuit. Students had the opportunity to discern that the "blue balls" (electrons) were part of the wires, battery, and bulb and observe variations in motion of the electrons. This prompted the students to consider electrons as energy transporters, as shown through student representations (see Fig. 5b).

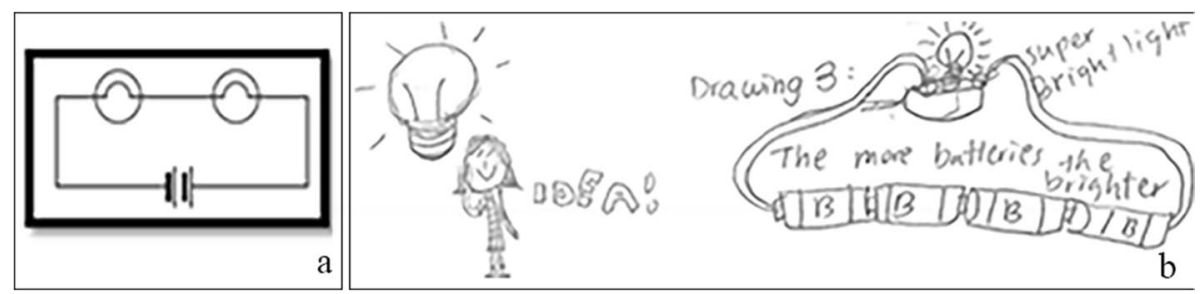

Fig. 3 a Canonical representations of an electric circuit, $\mathbf{b}$ student journal representation 
Fig. 4 Student journal representation communicating role of switch
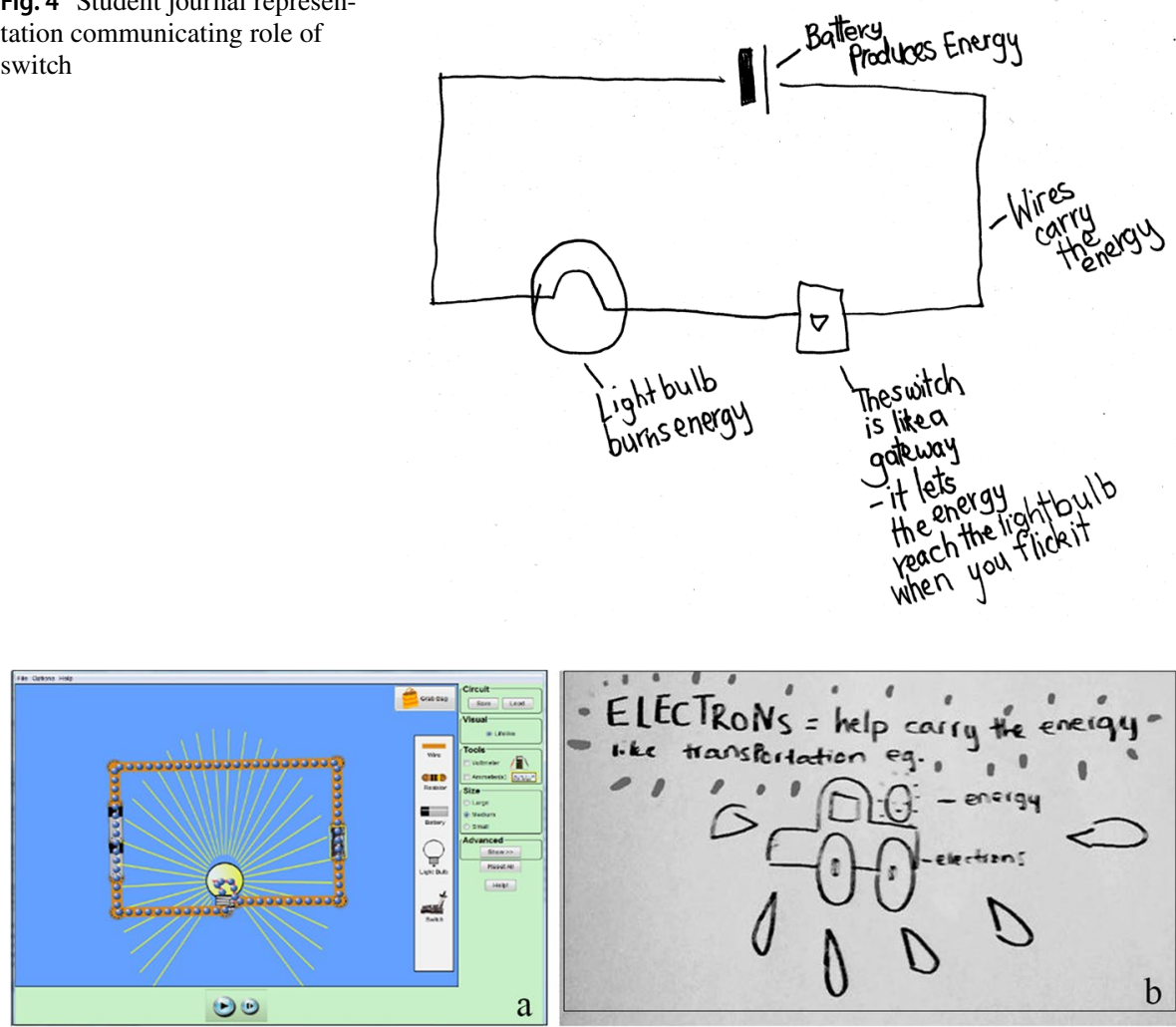

Fig. 5 a Virtual circuit, bright light with two batteries. b Student journal representation

Like example 1, Kate's selection of SRs was driven by ways to guide students' understanding by focusing on critical aspects of the object of learning (electric circuit function). Juxtaposing physical models, visual diagrams (with pictures and symbols), and dynamic simulations provided students opportunities to develop a deep understanding of a continuous loop and internal mechanisms that allow energy to flow. Students' attention was drawn through dimensions of variation enacted in the lessons to discern critical aspects of electric circuits (components, arrangement, and motion of energy). More complex patterns of variation were sequentially introduced over the three lessons. Each lesson facilitated students' noticing of the macroscopic, symbolic, and microscopic aspects of electric circuits and relationships between them.

\section{Example 3: Enactment, Discussion, and Critique of Analogical Models}

In lesson 5, Kate focused on critical aspects concerning electrons (exist in circuit parts, can move, and are energy carriers) to consolidate student meaning-making about electric circuits (from lesson 4). The design of this lesson oriented students to notice these dimensions of variation simultaneous with critical aspects of energy. Kate's choice of three analogical models and complimentary modalities supported the students in imagining the abstract processes within electric circuits. These three analogical models were: 

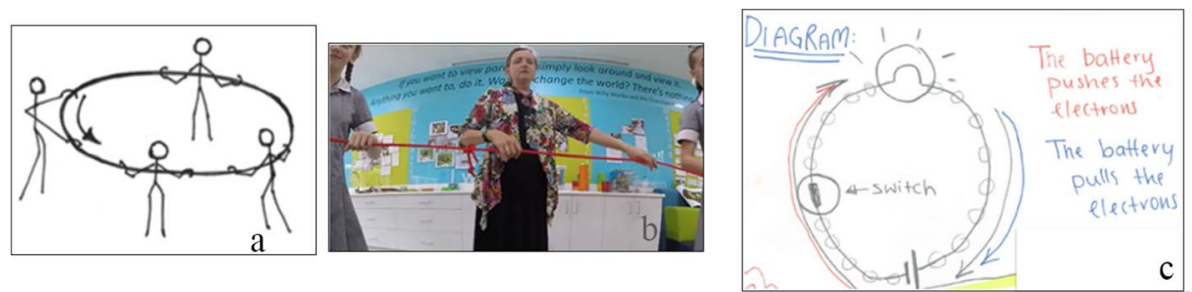

Fig. 6 a Sketch of the rope model, b demonstration, $\mathbf{c}$ journal representation

1) Rope model demonstration: rope shows electron connection and energy input (Fig. 6).

2) Delivery model: toy car "electrons" carry energy load (Fig. 7).

3) Wet ball model: students pass electron balls carrying water energy (Fig. 8).

Each model was purposeful in guiding students to discern the critical aspects required for understanding circuit function: (1) the electrons move together when pushed by energy from the battery, (2) electrons move and carry energy around the circuit in a pathway, and (3) energy changes into different forms within circuit components. Embodied and manipulative experiences helped students focus on specific aspects of circuit functioning and make sense of the physical and virtual circuits that they have constructed in previous lessons.
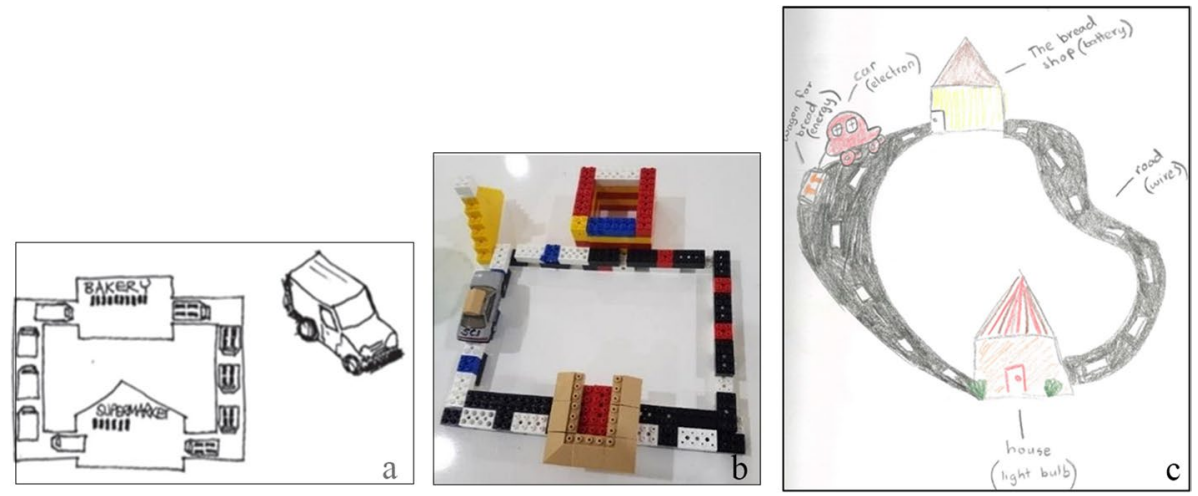

Fig. 7 a Sketch, b group 3D model, and c journal representation of model
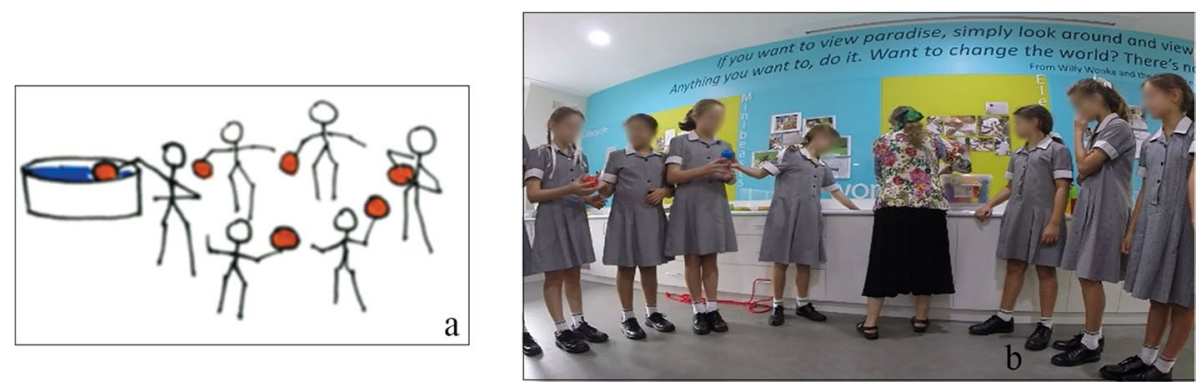

Fig. 8 Wet ball model a sketch, b students passing out balls before role playing the model 
Kate gave a verbal introduction about science models and how scientists used them to help build knowledge. Acting as a battery, Kate used a small circular rope held by three students acting as light bulbs to demonstrate model one (Fig. 6a, b). Kate pulled with one hand and pushed with the other to make the rope slide through the students' hands. An excerpt from class discussion shows how Kate helped students interpret the model:

T: What do you think the rope represents in this model?

S: Energy being transferred around the circuit.

T: Does it? There is energy being transferred around the circuit but what does the rope itself represent?

S: The wire, and the electrons going through it.

T: All right, and how the electrons are going through it. So, it's actually showing the electrons moving around in the wires. Because wires don't move around do, they? No, but the electrons do.

This model focused on the battery as the energy source that causes the electrons to move. The rope, representing adjacent electrons inside the wire, battery, and globe, showed electrons all moved instantly, rather than one after the other. The action "felt" immediately by the students acting as light bulbs accounted for why the lights turn on simultaneously. Students also identified what the model did and did not show about an electric circuit, e.g. doesn't show that the electrons carry energy. Students represented their thinking in journals before continuing the lesson (see Fig. 6c).

The delivery model that focused on electrons as energy carriers to provide a mechanism for energy transfer around the circuit was first verbally described by the teacher. The analogy comprised bread production at a bakery being transported to a supermarket by vans along a connected road. Next, students physically constructed a 3D model with Lego blocks and a toy car (see Fig. 7a, b). Each group used their model to act out and verbally explain the model to Kate.

Journal representations such as Fig. 7c showed students could equate the parts of their model to circuit components. The brief transcript shows how Kate used formative assessment to check student understanding of what the model does and does not show:

S: The bread shop gives the bread, and the car is the electrons moving around the wire carrying the bread, which represents the energy.

T: What sort of energy?

S: Electrical energy.

T: What doesn't your model show?

S: That there are lots of electrons.

The enactment of an embodied representation through role play with a wet ball focused students' attention on critical aspects of energy transfer and transformation (Fig. 8a). A circle of students represented the wire, each holding a plastic ball symbolising an electron, with one student acting as a switch and another as the bulb (Fig. 8b). Acting as the battery, Kate wet her ball indicating chemical energy changing to electrical energy before passing the ball to the next person, to go around the circle. The bulb student rubbed each ball on her jumper (showing transfer energy) and jumped up (signalling energy transformation). As the balls moved towards the battery, students noticed the balls were almost dry. When the switch student stepped out of the circle, ball passing immediately stopped. Kate used questions to verbally probe students' thinking: 
The water on the balls represents energy, what happens to that energy as it goes around the circuit? Where is there most energy? Where is the least energy? ... Have we lost any balls? So, if we have the same amount of balls, that means the electrons stay constant, they stay the same. But what does change?

Comparing and critiquing all three analogical models helped students to appreciate the partiality of models and recognise that no single model gave a complete explanation. This is evident in students' post-sequence interview comments:

I really liked it because if, say, I didn't get something in one model, and then we moved onto the next one, then I would get what it was meant to be.

In this example, the three models work together towards the object of learning; each model highlights a different dimension of the electric circuit concept. In the rope model, the variation comprised electrons inside the circuit pathway that were made to move by the battery. This explained the role of the battery as an energy source. The delivery model opened variations in ways in which electrons carry energy as they moved around the circuit pathway, drawing students' attention to the critical aspect of energy transfer but not transformation. The wet ball model exposed students to ideas of electrons collecting and losing energy at different points in the circuit, highlighting both transfer and transformation of energy. Including both transfer and transformation of energy in this wet ball model, the embodied representation allowed students to attend to several aspects of the energy concept simultaneously. Importantly, the final model created focal awareness of the critical aspects that had previously been considered one at a time and showed how they related to each other. Cumulatively, the models provided opportunities to develop and consolidate an increasingly sophisticated notion of energy within electric circuits.

\section{Discussion}

We explored how a RCA can facilitate the design of a multimodal teaching sequence about electric circuits for primary students and how its enactment might achieve a conceptual focus.

\section{Multimodal Teaching Sequence Design}

The results showed the teaching sequence design was framed around the four guiding principles (p. 3) of a RCA which we use to structure the discussion.

\section{Sequences of Representational Challenges}

Representational challenges were integral to the teaching sequence. Each challenge was conceptually focused, and multimodal representations were implicit in their solution. The challenges positioned students to "discover" key ideas (critical aspects) Kate had pre-determined, through interacting with SRs apt for their age. Example 1 showed how physical interactions with toys and visual dynamic animations helped raise students' awareness of energy as a fundamental idea. In example 2, representational challenge 1 (lesson 2) using minimal circuit components, students were impelled to notice a continuous loop was required to activate energy in a circuit. 
After time to explore and become familiar with different circuit components, challenge 2 (lesson 3) revealed the relationship between bulb brightness and battery energy input. Kate supported student inquiry and making claims about energy in electric circuits, by guiding student articulation of observations, questioning, and verbal discussion. Such interactions provided opportunities for students to build meaning. Exploring energy further, challenge 3, (lesson 4) steered students towards ideas about energy flow. The combined affordances of the SRs provided the possibilities for learning. The multimodal nature of the SRs allowed students to notice and consider electric circuits in different ways. Yore and Hand (2010) previously found transformation among multimodal representations had the greatest potential to promoting learning (p. 96).

Through solving the challenges, Kate supported students to construct and coordinate representations (between modes) to communicate their thinking and develop explanations about electric circuits. Aligning with Jewitt (2008), Kate's semiotic work involved strategic selection, sequencing, and connecting SRs. Further, she used SRs that were most apt to convey meaning for primary age students at given moments (Kress et al., 2014). Solving the representational challenges in succession scaffolded students to progressively discern critical aspects and construct energy-based explanatory accounts of electric circuits. Like Fredlund et al. (2021), VT was not part of the study design, so Kate was not conscious of creating variation. However, their conceptual focus and the way the representational challenges were enacted in the classroom facilitated students' discernment of critical aspects. Spaced throughout the sequence the representational challenges stimulated interest, sustained engagement, and gave Kate a means to direct the conceptual focus.

\section{Representations Are Explicitly Discussed}

Various multimodal representations were used as instructional tools and reasoning devices. An important teacher role in a RCA is the explicit discussion of representations. Example 1 showed Kate's dialogic guidance during whole class exploration of interactive simulations (Table 3). The simulations provided students with opportunities to relate the representation of abstract ideas to concrete objects. According to Olympiou et al. (2013), the unique affordances of the multi-representational nature of interactive simulations can provide a positive impact on student learning of abstract ideas.

Kate's focus on elements of the representational system, including symbols, provided students with representational tools to use in generating their own representations. She supported students to interpret the dynamic visualisations within simulations as explanatory accounts of complex systems. Hennessey, Deaney, and Ruthven (2006) suggested that interactive simulations may be used as a reasoning tool. In this research, primary students used simulations to explore and visualise the consequences of their inquiry, promoting reasoning.

Examples 1-3 showed how multiple SRs provided opportunities for students to discern energy and electron flow concepts within the dynamic processes of an electric circuit. Students showed understanding that several representations are required for working with multiple aspects of a concept (Tytler et al., 2013). Later in the teaching sequence (lesson 5), students explored models, and each was viewed as limited in their explanatory power. The abilities of students to construct novel representations and critique existing representations enhance what diSessa (2004) has termed metarepresentational competence. Jadrich and Bruxvoort (2011) suggest that if students are constructing and evaluating models, then they 
are involved in scientific inquiry, which can lead to a more informed view of the nature of science (Schwarz \& Gwekwerere, 2007).

A key finding that parallel's Fredlund et al.'s (2021) study with secondary students is the pivotal role of the teacher in aiding students to "see" the variation relevant in specific situations. Thus, verbal interactive discussion was essential to galvanise students' thinking by directing their noticing towards critical aspects.

\section{Meaningful Learning Involves Representational/Perceptual Mapping}

Opportunities for meaningful learning were scaffolded using diverse perceptual experiences. SRs supported student mapping between the phenomenon and representations. In example 1, teacher demonstration plus hands-on activities provided the perceptual basis for students to link their experience with ideas about energy from discussion of the PhET animations. Likewise, example 2 provided opportunities for students to construct physical circuits gaining perceptual experience before representing their ideas in journals. The provision of hands-on and virtual explorations of electric circuit provided students with optimal learning opportunities (Zacharia \& de Jong, 2014).

In example 3, the three models of the same phenomenon allowed the students to attend to different aspects, source of energy, transfer, and transformation, of energy in an electric circuit. Each model had a specific affordance that focused students towards one or more critical aspects. Previous studies have shown enhanced understanding may result from interaction with different representations of the same concept (Hoban \& Nielsen, 2013; Prain \& Waldrip, 2006).

Kate's work positioned the students to translate meaning between various representational forms (Prain \& Tytler, 2012) and a wide range of perceptual/experiential contexts. The sequence design provided opportunities to synthesise key ideas from multimodal representations (such as physical models and resources, animations, visual, verbal) to generate understanding about electric circuits. This supports Wilson and Bradbury's (2016) conclusion that multimodal curricular units benefit primary student learning and enhance depth of understanding. The SRs supplement each other in the communication process. Hands-on tasks alone are insufficient for conceptual meaning-making. The acts of exploring, representing, reflecting from explicit discussion, and re-representing provide opportunities for student learning.

\section{Ongoing Formative and Summative Assessment}

The structure of the sequence and its emphasis on key concepts led to a continuous checking and re-checking of students' developing understanding. Formative assessment was part of the sequence design. Annotating the light bulb diagram in example 1, journal representations (examples 1 and 2), submission of switch description (example 2), and verbal explanations of the bread model (example 3) are examples of how Kate embedded assessment of student's developing explanatory accounts of electric circuits. Kate used student feedback to reflect on the effectiveness of the SRs in aiding their idea-building. The feedback helped Kate see what was relevant for her primary students to access the concepts. From a VT perspective, thinking about the object of learning and how students can come to realise the critical aspects through the SRs used raises the teacher's consciousness of students' learning (Fredlund, Linder, \& Airey, 2015a). 


\section{Enactment of Teaching Sequence}

Implementing a RCA necessitates a conceptual focus. Various opportunities for meaning-making arising from learning experiences could result in varied conceptions. Crucially, the teacher's role is to direct students' attention to ideas that matter. Kate's enactment of the sequence involved targeting specific aspects of energy and progressive building of key ideas. Students' explanative representations of electric circuit became cumulatively deeper. The lessons orchestrated a deliberate sequence that targeted students' noticing of critical aspects through variations, energy: exists (a phenomenon), can get from place to place (transfer), movement can be controlled (switch), and can be different forms (transformation). These critical ideas underpin an understanding of how electric circuits generate electricity at a conceptual level. The analysis helped us understand what Kate did to create apt conditions for learning and how she enacted those conditions in the classroom, to construct a focal awareness around energy as a central concept.

Targeting of key ideas commenced with energy in lesson 1. Time to explore familiar toys helped students notice energy in everyday contexts before attending to energy types and changes in systems using digital animations. In example 2, the energy concept was materialised, as students engaged in experiential learning linked to electric circuits. The lesson order was intentional to introduce ideas about energy, the macroscopic processes of electric circuits, and electron role sequentially. The multimodal inquiry learning experiences in the sequence provided students with representational tools to explore and develop more detailed and complex explanatory accounts of electric circuit behaviour. A teaching sequence reliant on multimodality allowed students the opportunity to learn by moving between and integrating semiotic resources and produce meaning through a variety of ways of representing abstract or technical ideas (Kress et al., 2014). Kate's enactment of the sequence had the effect of highlighting which aspects of knowledge were vital for students to know and involved trying to feature this in ways that made the meaning accessible. The RCA helped Kate identify and enact the critical aspects of an object of learning (Fredlund, Linder, \& Airey, 2015a), the electric circuit, necessary to make learning possible (Lo \& Marton, 2011; Marton et al., 2004; Marton \& Booth, 1997).

From a VT perspective, more complex patterns of variation were sequentially introduced and enacted over the sequence. These support students attending to the macroscopic, symbolic, and microscopic aspects of the electric circuits and the relationships among these different aspects. Students discerned these key aspects one at a time. An increasing sophisticated conception of electric circuits was developed as ideas were progressively added. Eventually related ideas were brought together enabling simultaneous discernment to achieve fusion (Marton, 2014). This final step was manifested in lesson 5 that involved the use of three analogical models. Each model highlighted critical aspects of energy that built on each other to account for the macroscopic observations established by the students. The rope model represents how energy from the battery causes electrons to move. The delivery model represents how flowing electrons enable energy to travel (transfer) around the connected path. The wet ball model represents energy changes (transforms) at certain places (components). This sequence of representations and models provided opportunities for students to develop a cumulative understanding of macroscopic and microscopic view of the electric circuit function. Hoban and Nielsen (2013) label this as a "cumulative semiotic pathway" (p. 140) whereby students build meaning from one model to the next. 


\section{Complementary Analysis Lenses}

Our research revealed that multimodality and VT were complementary in providing insight into how Kate created conditions necessary for learning about electric circuits using a RCA. The use of varied SRs and representational modes singularly and in combination afforded students different views of circuits and reinforced developing ideas about energy. VT provided the language to talk about what was made possible for students to learn using patterns of variation and how students made use of these possibilities. The multimodal analysis of the sequence generated insights into how each dimension of variation was enacted in the classroom through purposeful selection and sequencing of SRs across multiple modes. This way of analysing and conceptualising how the teacher communicated with her students is an aspect that requires further attention in the development of VT. The concept of modal affordance "what is possible to express and represent easily" (Jewitt, 2008. p. 247) can correspond with the notion of what is made possible to learn (Marton, 2014).

Abstract ideas and explanatory accounts were coordinated using dynamic, visual, and embodied models. Students were guided to discern the critical aspects separately and then simultaneously. The selective use of SRs to clarify and bring together critical aspects of electric circuits was instrumental for student understanding. Future research work combining the two theoretical frameworks in other topic areas could potentially contribute to both theory development. Juxtaposing and connecting theories of the learning tasks, of learner attributes, and of processes of knowledge acquisition and classroom participation can better inform classroom practice. The multimodal and variation theory perspectives highlight the complex pedagogic work of designing lesson sequences across modes in the classroom (Jewitt, 2008).

\section{Conclusion}

The study showed the principles of a RCA framed the design of a multimodal, inquirybased teaching sequence to make learning abstract ideas about electric circuits possible for primary students. The multimodality analysis lens revealed the importance of the teacher's selection of various SRs most appropriate for students to access, personally signify, and re-represent discrete ideas to make meaning. The lens of VT provided insights into how the teaching sequence was enacted, varying ideas one by one before relating them to each other. We conclude that teachers should help students to discern three critical aspects of electric circuits (energy input, energy transfer, and energy transformation). A RCA approach can facilitate this outcome.

The study implies that multimodality can support the pedagogical task of developing year 6 students' explicit understanding of abstract concepts. Teaching complex phenomena, such as electric circuit behaviour, requires strategic design of inquiry-based lesson sequences. Learning tasks should attend to critical aspects of the intended concepts and phenomena and connect students' representational contributions to the canonical representational forms. Energy as a central concept with underlying critical aspects is appropriate for teaching about electric circuits at the primary level. Teaching sequence design entails a conceptual focus, the selection and sequencing of SRs, and multimodal representations to clarify critical aspects and facilitate links to the observed phenomena. SR selection and placement should introduce the dimensions of the intended learning object; direct attention 
to the critical aspect using patterns of variations (contrast, separation, generalisation, and fusion), and guide students' experience towards a differentiated and integrated concept. Finally, teachers should develop students' metarepresentational competence to maximise their learning within multimodal learning environments. We argue that a multimodal teaching sequence that integrates SRs and creates variation, reinforced by explicit teacherled discussion, can create possibilities for primary students to learn about electric circuits and potentially other science concepts.

Funding Open Access funding enabled and organized by CAUL and its Member Institutions.

Open Access This article is licensed under a Creative Commons Attribution 4.0 International License, which permits use, sharing, adaptation, distribution and reproduction in any medium or format, as long as you give appropriate credit to the original author(s) and the source, provide a link to the Creative Commons licence, and indicate if changes were made. The images or other third party material in this article are included in the article's Creative Commons licence, unless indicated otherwise in a credit line to the material. If material is not included in the article's Creative Commons licence and your intended use is not permitted by statutory regulation or exceeds the permitted use, you will need to obtain permission directly from the copyright holder. To view a copy of this licence, visit http://creativecommons.org/licenses/by/4.0/.

\section{References}

Aboagye, G., Ossei-Anto, T., \& Ampiah, J. (2018). Combining inquiry-based hands-on and simulation methods with cooperative learning on students' learning outcomes in electric circuits. American Journal of Educational Research, 6(8), 1172-1181.

Anderson, T., \& Shattuck, J. (2012). Design-based research: A decade of progress in education research. Educational Researcher, 41(1), 16-25.

Australian Curriculum, Assessment and Reporting Authority (ACARA) (2019). Australian Curriculum: Science. Retrieved from http://www.australiancurriculum.edu.au/science

Carolan, J., Prain, V., \& Waldrip, B. (2008). Using representations for teaching and learning in science. Teaching Science, 54(1), 18-23.

Chapman, S. (2014). The 'big ideas' of electricity at primary school. Primary Science, 135, 5-8.

Chi, M. (2009). Active-constructive-interactive: A conceptual framework for differentiating learning activities. Topics in Cognitive Science, 1, 73-105.

Chiu, M.-H., \& Lin, J.-W. (2005). Promoting fourth graders' conceptual change of their understanding of electric current via multiple analogies. Journal of Research in Science Teaching, 42(4), 429-464.

Cox, R. (1999). Representation construction, externalized cognition and individual differences. Learning and Instruction, 9, 343-363.

De Carvalho, R. (2019). Embodied learning and multimodality in science education: teachers' perceptions of teaching electrical circuits, their diagrammatic symbols, physical components and functions through multisensory approach. Research in Teacher Education, 9(1), 12-18.

diSessa, A. A. (2004). Metarepresentation: Native competence and targets for instruction. Cognition and Instruction, 22, 293-331.

Eriksson, M., Eriksson, U., \& Linder, C. (2020). Using social semiotics and variation theory to analyse learning challenges in physics: A methodological case study. European Journal of Physics, 41(6), 065705 .

Fredette, N., \& Lochhead, J. (1980). Student conceptions of simple circuits. The Physics Teacher, 18(3), 194-198.

Fredlund, T., Beate Remmen, K., \& Knain, E. (2021). The epistemological commitments of modes: Opportunities and challenges for science learning. Visual Communication, 14703572211038991.

Fredlund, T., Linder, C., \& Airey, J. (2015a). A social semiotic approach to identifying critical aspects. International Journal for Lesson and Learning Studies.

Fredlund, T., Airey, J., \& Linder, C. (2015b). Enhancing the possibilities for learning: Variation of disciplinary-relevant aspects in physics representations. European Journal of Physics, 36(5), 055001. 
Furtak, E., Seidel, T., Iverson, H., \& Briggs, D. (2012). Experimental and quasi-experimental studies of inquiry-based science teaching: A meta-analysis. Review of Educational Research, 82(3), 300-329.

Gibson, J. (1977). The theory of affordances. In R. Shaw \& J. Bransford (Eds.), Perceiving, acting, and knowing: Toward an ecological psychology (pp. 67-82). Erlbaum.

Greeno, J. G., \& Hall, R. P. (1997). Practicing representation: Learning with and about representational forms. Phi Delta Kappan, 78(5), 361-368.

Hart, C. (2008). Models in physics, models for physics learning, and why the distinction may matter in the case of electric circuits. Research in Science Education, 38, 529-544.

Hoban, G., \& Nielsen, W. (2013). Learning science through creating a 'slowmation': A case study of preservice primary teachers. International Journal of Science Education, 35(1), 119-146.

Hubber, P. (2018). Electricity. In K. Skamp \& C. Preston (Eds.), Teaching primary science constructively (6th ed., pp. 194-224). Cengage Learning Australia.

Hubber, P., \& Chittleborough, G. (2015). Teacher change in implementing a research-developed representation construction pedagogy. Il Nuovo Cimento, 38(3), 1-12.

Hubber, P., Tytler, R., \& Chittleborough, G. (2018). Representation construction: A guided inquiry approach for science education. In R. Jorgensen, H. Kanasa, \& K. Larkin (Eds.), STEM education in the Junior Secondary - The state of play (pp. 57-89). Springer Nature.

Hubber, P., Tytler, R., \& Haslam, F. (2010). Teaching and learning about force with a representational focus: Pedagogy and teacher change. Research in Science Education, 40(1), 5-28.

Jaakkola, T., Nurmi, S., \& Veermans, K. (2011). A comparison of students' conceptual understanding of electric circuits in simulation only and simulation laboratory contexts. Journal of Research in Science Teaching, 48(1), 71-93.

Jadrich, J., \& Bruxvoort, C. (2011). Learning and teaching scientific inquiry: Research and applications. NSTA Press.

Jewitt, C. (2008). Multimodality and literacy in school classrooms. Review of Research in Education, 32, 241-267.

Jewitt, C., Bezemer, J., \& O’Halloran, K. (2016). Introducing multimodality. Routledge.

Kress, G., Jewitt, C., Ogborn, J., \& Tsatsarelis, C. (2014). Multimodal teaching and learning: The rhetorics of the science classroom. Continuum.

Lemke, J. (1998). Multiplying meaning: Visual and verbal semiotics in scientific text, in J. Martin and R. Veel (eds.), Reading Science. London: Routledge

Lo, M. L. (2012). Variation theory and the improvement of teaching and learning. Göteborgs Universitet, Acta Universitatis Gothoburgensis, Göteborg

Lo, M. L., \& Marton, F. (2011). Towards a science of the art of teaching. International Journal for Lesson and Learning Studies, 1(1), 7-22.

Marton, F. (2014). Necessary conditions of learning. Routledge.

Marton, F., \& Booth, S. (1997). Learning and awareness. L. Erlbaum Associates.

Marton, F., Runesson, U., \& Tsui, A. (2004). The space of learning. In F. Marton \& A. B. M. Tsui (Eds.), Classroom discourse and the space of learning (pp. 3-42). Lawrence Erlbaum Associates.

Miller, R. (2005). Teaching about energy. Department of Education Studies: Research Paper 2005/11, The University of York.

National Research Council. (2013). Next generation science standards: For states, by states. The National Academies Press.

Olympiou, G., Zacharias, Z., \& deJong, T. (2013). Making the invisible visible: Enhancing students' conceptual understanding by introducing representations of abstract objects in a simulation. Instructional Science, 41, 575-596. https://doi.org/10.1007/s11251-012-9245-2

Pang, M. F. (2003). Two faces of variation: On continuity in the phenomenographic movement. Scandinavian Journal of Educational Research, 47(2), 145-156.

Prain, V., \& Tytler, R. (2012). Learning through constructing representations in science: A framework of representational construction affordances. International Journal of Science Education, 34(17), 2751-2772.

Prain, V., \& Waldrip, B. (2006). An exploratory study of teacher's and students' use of multi-modal representations of concepts in primary science. International Journal of Science Education, 28(15), 1843-1866.

Prain, V., Waldrip, B., \& Carolan, J. (2007). Representational opportunities and learning in science. Paper presented at the Australasian Science Education Research Association Conference, Fremantle, July 12-14.

Preston, C., Hubber, P., Bondurant-Scott, M., \& Gunesekere, I. (2020). A representation construction approach to learning about electrical energy in year 6. Teaching Science, 66(2), 5-19. 
Preston, C. (2017). Effect of a diagram on primary students understanding about electric circuits. Research in Science Education, 49(5), 1433-1456.

Runesson, U. (2005). Beyond discourse and interaction. Variation: A critical aspect for teaching and learning mathematics. Cambridge Journal of Education, 35(1), 69-87.

Runesson, U. (2006). What is it possible to learn? On variation as a necessary condition for learning. Scandinavian Journal of Educational Research, 50(4), 397-410.

Schwarz, C., \& Gwekwerere, Y. (2007). Using a guided inquiry and modelling instructional framework (EIMA) to support pre-service K-8 science teaching. Science Education, 19, 158-186.

Tan, Y. S. M., Amiel, J. J., \& Cheng, C. (2020). Theorizing variation theory-A case of collaborative action research involving science teacher candidates. Educational Action Research, 28(3), 443-461.

Tang, K. S., Delgado, C., \& Moje, E. B. (2014). An integrative framework for the analysis of multiple and multimodal representations for meaning-making in science education. Science Education, 98(2), 305-326.

Tytler, R., Peterson, S., \& Prain, V. (2006). Picturing evaporation: Learning science literacy through a particle representation. Teaching Science, 52(1), 12-17.

Tytler, R., Prain, V., Hubber, P., \& Waldrip, B. (Eds.). (2013). Constructing representations to learn in science. Sense Publishers. https://doi.org/10.1007/978-94-6209-203-7_7

Tytler, R., Prain, V., Aranda, G., Ferguson, J., \& Gorur, R. (2020). Drawing to reason and learn in science. Journal of Research in Science Teaching, 57(2), 209-231.

Van Leeuwen, T. (2005). Introducing social semiotics. Routledge.

Waldrip, B., Prain, V., \& Carolan, J. (2010). Using multi-modal representations to improve learning in junior secondary science. Research in Science Education, 40(1), 65-80.

Wilson, R. E., \& Bradbury, L. U. (2016). The pedagogical potential of drawing and writing in a primary science unit. International Journal of Science Education, 38(17), 2621-2641.

Yeo, J., \& Nielsen, W. (2020). Multimodal science teaching and learning. Learning: Research and Practice, $6(1), 1-4$.

Yore, L. D., \& Hand, B. (2010). Epilogue: Plotting a research agenda for multiple representations, multiple modality, and multimodal representational competency. Research in Science Education, 40(1), 93-101.

Zacharia, Z., \& de Jong, T. (2014). The effects on students' conceptual understanding of electric circuits of introducing virtual manipulatives within a physical manipulatives-oriented curriculum. Cognition and Instruction, 32(2), 101-158. https://doi.org/10.1080/07370008.2014.887083

Publisher's Note Springer Nature remains neutral with regard to jurisdictional claims in published maps and institutional affiliations. 